\title{
Relação médico-paciente em oncologia: medos, angústias e habilidades comunicacionais de médicos na cidade de Fortaleza (CE)
}

\author{
Relation doctor-patient in oncology: \\ fears, anguishes and communication abilities \\ among doctors in Fortaleza, Ceará State, Brazil
}

\author{
Carlos M aximiliano Gaspar Carvalho H eil Silva ${ }^{1}$ \\ Camila Herculano Soares Rodrigues ${ }^{2}$ \\ JussiêCorreia Lima² \\ N atália Braga H ortêncio Jucá ${ }^{3}$ \\ Kathiane Lustosa A ugusto ${ }^{1}$ \\ Carolina Arcanjo Lino ${ }^{1}$ \\ Amanda Gisele N obre Carvalho ${ }^{1}$ \\ Filipe Castro deAndrade ${ }^{1}$ \\ JosianeVasconcelos Rodrigues ${ }^{1}$ \\ Andrea Caprara ${ }^{1}$
}

${ }^{1} U$ niversidade Estadual do Ceará, Centro de Ciências da Saúde. Av. Paranjana 1.700, Campus do Itaperi. 60740-000 Fortaleza CE. carlmaxbr@hotmail.com ${ }^{2}$ Grupo Humanidades,

Saberes e Práticas em Saúde, Universidade Estadual do Ceará.

${ }^{3}$ Fundação Cearense de A poio ao Desenvolvimento Científico e Tecnológico,
Abstract In oncology the doctor-patient relationship has a particular importance due to the gravity of the illness and to the stigma that is followed many times by the experience of the patient. This research was designed to analyze perceptions and difficulties that doctors face when they are dealing with oncology patient. It is a qualitative study, based mainly on open and in-depth interviews, involving 20 doctors from the Cancer Institute of Ceará. From the relationship of Dr. Sheila with her patients, Cássio and Elisa, fictitious personages of a chronicle larded in the quarrel of the article, the main facts are illustrated. We tried to approach four main subjects: the construction of the bond, the communication abilities performance, the therapeutic approach and the family interaction. The suffering and the emotional implications of patients and familiars, the differences in communication between the interviewed doctors, mainly in reference to the transmission of the diagnosis and the therapy, become important factors that influence the relation and the establishment or not of the therapeutic bond. Because of this, it seems to be necessary studies and debates concerning this subject, aiming at an incorporation of this thematic in the medical training. Key words Doctor-patient relationship, Oncology, Therapeutic bond, Communication abilities, Family, Medical education
Resumo A relação médico-paciente, em oncologia, adquire uma particular importância devido à gravidade da doença eao estigma quemuitasvezes acompanha a experiência do paciente. Esta pesquisa teve como objetivo analisar percepções e dificuldades que os médicos vivenciam frente ao paciente oncológico. Trata-se de um estudo qualitativo, baseado principalmente em entrevistas abertas e aprofundadas, realizado com vinte médicos que trabalham no Instituto do Câncer do Ceará. Baseando-se na convivência da Dra. Sheila com seus pacientes, Cássio eElisa, personagens fictícios de uma crônica entremeada na discussão do artigo, ilustram-se os principais registros encontrados. Procurou-se abordar quatro temas centrais: a construção do vínculo, o desempenho de habilidades comunicacionais, a abordagem terapêutica ea interação com a família. 0 sofrimento e as implicações emocionais de pacientes e familiares, as diferenças comunicacionais existentes entre os mé dicos entrevistados, principalmente em referência à transmi ssão do diagnóstico e à terapêutica, tornam-se fatores importantes que influenciam a relação e o estabel ecimento ou não do vínculo terapêutico. Diante disso, vê se ser necessário estudos e debates acerca do tema, visando a uma incorporação desta temática na formação médica.

Palavras-chave Relação médico-paciente, Oncologia, Vínculo terapêutico, $\mathrm{H}$ abilidades comunicacionais, Família, Educação médica 


\section{Introdução}

A relação médico-paciente é uma temática que, atualmente, encontra um renovado interesse na comunidade científica, na formação e na prática médica. Trata-se de uma aprendizagem indispensável para uma intervenção médica eficaz, que perceba o processo do adoecer sob a ótica daquele pacienteque se insere em uma experiência de fragilidade e de ameaça ao seu estado de ser saudável eativo.

Diversos trabalhos mostram que a maioria das queixas dos pacientes faz referência a dificuldades comunicacionais com o médico e não a sua competência clínica, apontando queum bom relacionamento aumenta a satisfação do paciente e a qualidade do serviço de saúde, além de influenciar positivamente 0 estado de saúde do paciente ${ }^{1,2}$. Não é suficiente, portanto, buscar novas tecnologias e boa formação dos profissionais médicos para atingir níveis de excelência em saúde; é necessário também o respeito dos valores subjetivos do paciente, a promoção de sua autonomia e a tutela das diversidades culturais ${ }^{3}$.

Sob a perspectiva da oncologia, nota-se que esta relação carrega peculiaridades que Ihe são próprias. Por se tratar de uma doença percebida como traumatizante, perante o imaginário pessoal e coletivo, sua abordagem torna-se especialmente difícil. Angústias, medos e sofrimentos apresentam-se na vida dos pacientes e de suas famílias, necessitando estabelecer um vínculo com o profissional como coadjuvante terapêutico.

O bserva-se, então, durante a consulta oncológica, a presença de grande ansiedade por parte do pacientee do médico. Junto ao diagnóstico de câncer, leva-se consigo vários estigmas e, com eles, grande impacto na dimensão emocional do paciente ${ }^{4,5}$. Além disso, a família do pacientetambém é alvo e origem de estresses emocionais ${ }^{6}$. 0 próprio tratamento égerador de morbidadee de uma tensão adicional7-9. Esses aspectos devem ser considerados pelo médico, que, por sua vez, também experimenta sentimentos provocados pela doença do paciente.

No intuito de minimizar essas dificuldades, em 1992, Buckman publicou o protocolo SPI$K E S$, queéaté hoje uma das referências metodológicas mais adotadas a nível internacional na comunicação demás notícias ${ }^{10}$. Em 2000, foi publicado um artigo que direciona e adapta o protocolo SPIKES para o contexto da oncologia' ${ }^{11}$.

A proposta de Buckman identifica seis passos de comunicação de uma má notícia. 0 primeiro passo, setting up, seria a preparação da entrevista, tanto a escolha do lugar ideal, como a forma de se apresentar ao paciente. 0 segundo, perception, consiste em avaliar o que o paciente já conhece sobre sua doença e a percepção que tem dela. 0 terceiro, invitation, seria a fase em que se avalia até que ponto o paciente deseja saber de sua condição, para que o médico não ultrapasse o limite do pacientee transmita detalhes queestenão desejava ouvir. 0 quarto passo, knowledge, seria o momento em queo médico transmite, de fato, a má notícia. É indicado que não se use palavras técnicas e sim termos de fácil compreensão para o paciente e que se transmita a verdade, evitando grosserias. 0 quinto, emotions, éa fase em quesetrabalham as reações emocionais do paciente de forma empática. Por fim, 0 sexto passo, strategy and summary, seria 0 momento de apresentar e discutir o plano terapêutico e o prognóstico, alimentando expectativas reais e considerando a autonomia do paciente na escolha do tratamento.

Esse protocolo, por conseguinte, torna-se fundamental, sobretudo durante o acompanhamento de pacientes oncológicos, no qual o médico se vêfrequentementeem uma situação em que é preciso transmitir uma má notícia, seja um diagnóstico, um prognóstico, uma falha terapêutica ou um efeito adverso. Na maioria das vezes, o médico não foi devidamente treinado para ge renciar essas situações, levando em conta aspectos psicossociais do paciente, e precisa aprender sozinho a desenvolver habilidades relacionais e comunicacionais não ensinadas na formação acadêmica. $E$, mais que isso, a aprender a lidar com a terminalidade do próximo, o que resgata a sua própria natureza mortal.

0 exercício da medicina é, portanto, particularmentena oncologia, inevitavelmentepermeado por angústias e dilemas. Entretanto, se essa problemática fosse satisfatoriamente abordada dentro dos currículos médicos, os danos, tanto à saúde mental do profissional quanto à relação médico-paciente, poderiam ser sensivelmentere duzidos. A subjetividade que a prática médica impõe merece ser curricularmente contemplada com a mesma ênfase que a objetividade tem merecido nas escolas médicas ${ }^{12}$.

Este trabalho, desse modo, visa analisar as percepções e dificuldades da relação médico-paciente, na visão dos médicos, frente ao paciente oncológico, destacando os aspectos relacionados à transmissão demá notícia, desempenho do tratamento, evolução da doença e a relação com os familiares. 


\section{Metodologia}

A presente pesquisa consiste em um estudo qualitativo baseado em entrevistas abertas com mé dicos que trabalham com pacientes com câncer no âmbito hospitalar da cidade de Fortaleza. Numa seleção aleatória, entrevistaram-se vinte médicos de ambos os sexos com tempo de serviço variável, de quatro a vinte e oito anos de formados, do Hospital do Câncer do Ceará (ICC), instituição filantrópica com assistência pelo SUS, referência no estado. Do corpo clínico total do ICC, selecionou-se um total de 76 médicos que tinham um contato direto com paciente, do qual o grupo estudado representaria $25 \%$ aproximadamente.

Dessa forma, os dados foram coletados por meio de uma guia de perguntas abertas que busca propiciar respostas espontâneas e não monossilábicas. 0 objetivo, com isso, era obter, por meio de análise, a identificação e interpretação das percepções dos sujeitos estudados. As perguntas procuravam abordar diversos temas, os quais seriam as principais dificuldades na abordagem do paciente oncológico: como proceder quando é necessário dar uma má notícia; quais fatores na relação médico-pacientepodem influenciar o prognóstico de pacientes oncológicos; como indicar o melhor tratamento para cada paciente ecomo a família podeinfluenciar a relação médico-paciente na oncologia.

Os dados obtidos na entrevista foram analisados qualitativamente com base nos objetivose no referencial teórico referente ao tema proposto. Através da análise dos discursos das perguntas que abordavam as características na relação médico-paciente oncológico, chegou-seà divisão de categorias analíticas que forneceram a base da interpretação. Foram identificadas quatro categorias principais, as quais dissertam sobre as dificuldades na construção do vínculo, no desempenho de habilidades comunicacionais, na abordagem terapêutica e na interação com a família. Com intuito de ilustrar essas categorias, baseando-se no material coletado durante as entrevistas, desenvolveu-se uma história fictícia de uma médica, doutora Sheila, que vive as dificuldades no relacionamento com pacientes oncológicos, Cássio e Elisa.

Por fim, ressalta-se que foram cumpridas as determinações da Resolução n 196/96 (ConseIho Nacional de Saúde - CNS) sobre pesquisa com seres humanos e que a coleta de dados iniciou-se após aprovação do projeto, elaborado de acordo com as diretrizes do CNS, pelo Comi- tê de Ética em Pesquisa (CEP) da instituição em que 0 estudo foi realizado, com a participação dos médicos ocorrendo de forma anônima, voluntária e com consentimento informado. Nesse sentido, os nomes utilizados para identificação dos entrevistados são fictícios.

\section{A construção do vínculo} ea definição diagnóstica

Dra. Sheila recebe em seu ambulatório Cássio, 41 anos, casado, chefe de família, quatro filhos, humilde, com fáscies de abatimento demonstrando uma vida não tão fácil assim. Cássio senta-se na cadeira de frente à médica e inicia seu relato. Informa que há algum tempo vem sentindo que aquel a vitalidade que portava anteriormentenão é mesma, não estando disposto nem para se alimentar, perdendo com isso alguns quilos, da ordem dedez nesse último semestre. Além disso, reclama de uma leve dor no pé do estômago a qual incomoda bastante. Relata que há dois meses peregrina por serviços médicos sem sucesso, apenas com receitas de anti-helmínticos e antiácidos. Traz um envelopecom vários exames. Dentre hemogramas, exames bioquímicos e parasitológico defezes, Dra. Sheila destaca uma endoscopia, bem catedrática em sua descrição: mucosa gástrica evidenciando úlcera infiltrante com margens rasas e pouco definidas; acompanhada em anexo de uma biópsia, que o paciente notificava ter recebido ontem, sucinta em sua conclusão: adenocarcinoma gástrico invasivo.

Nesse momento, suspira. Por mais corriqueiro que seja em sua vida profissional, ela não se acostuma. Não é fácil dizer para al guém que ele está com câncer, doença representada pelo imaginário geral como algo negativo, invasivo e limitante. E agora? Deve-se contar ao paciente 0 quetem? Falar não vai ser prejudicial? Seele souber, não vai piorar? São perguntas capazes inibir, adiar ou cancelar a atuação do profissional, formuladas diante desses contextos sempre com muita apreensão e receio pela maneira como 0 pacientevai reagir.

$\mathrm{N}$ a pesquisa, todos os médicos entrevistados reconhecem o paciente oncológico como sendo especial, fragilizado, inseguro, requerendo para o seu cuidado, além deum saber técnico-científico, uma sensibilidade dirigida ao humano ali envolvido, apontando, em sua totalidade, como uma grande dificuldade na construção do vínculo a própria estigmatização da doença: “A principal dificuldade é o preconcei to em relação ao cân- 
cer. M edo de morrer, medo do tratamento que refletem no preconceito e não numa experiência vivida". (Dra. Velma, 35 anos).

"Existeum estigma, masquenem sempreéverdade, queéuma sentença demorte, praticamente". (Dr. Thiago, 32 anos).

Somando a isso, condizente com as angústias de Dra. Sheila, a maioria dos médicos concorda que tais peculiaridades da doença neoplásica trazem elevados níveis de ansiedade e medo de comunicar a notícia, sentimentos que advêm especialmente da falta de preparo técnico para lidar com a gama de emoções que o paciente aflora no momento do diagnóstico: "O paciente oncológico é particular. Chega pra você com atitude desesperada, com atitude de urgência. Isso é uma coisa que confronta com o treinamento que você recebe deatender o pacientecom calma". (Dr. Maurício, 32 anos).

"O paciente geralmente chega amedrontado. Tende até a negar a questão da doença pelo medo da gravidade". (Dra. Núbia, 48 anos).

Dentro do contexto terapêutico, a qualidade ea forma de vínculo são de extrema importância por influenciar tanto no desenvolvimento quanto na qualidade do processo, pois sem vínculo a terapia não acontece. Assim, na busca da empatia pela construção do vínculo, observa-se a tentativa da maioria dos médicos de dizer a verdade e ser honesto com o paciente: "É o desenvolvimento da confiança, a segurança do paciente, as informações serem repassadas pra ele, tudo isso está junto para que o tratamento tenha boas condições de ter sucesso". (Dr. Thiago, 32 anos).

"Às vezes, o paciente precisa saber da real situação, mesmo que o prognóstico seja ruim, porqueo paciente deve dar um jeito na vida dele. Tem que colocar as prestações da casa em dia, o carro que tem prestação a vencer. $E$ as pessoas podem ajeitar a vida dele. A inverdade podevirar uma arma contra você. Você paga um preço por isso. Você tem que ser objetivo, real, verdadeiro". (Dr. Humberto, 44 anos).

Além disso, baseando-se nas entrevistas, como reforça Videla ${ }^{13}$, os pacientes têm fome de solidariedade porque a enfermidade, muitas vezes, humilha, corrói o sentido do "eu", tornandoos vulneráveis à palavra do médico. Assim, associando a verdade a seus discursos, o médico pode saciar a fome de solidariedade do paciente com conversas terapêuticas e tentativas de resgate de uma "esperança" ética, que, inclusive, pode ajudar a instalar no paciente uma busca interna de cura, o queémelhor explicitado pela frase de $D r$. Humberto: "Tem que ser verdadeiro, dando con- forto, dando esperança, nunca tire as esperanças. M esmo quando o prognóstico émuito ruim. Q uando o paciente tem alguns meses, você diz que a doença émuito grave. Q ueeletem delutar com a fé dele". (Dr. Humberto, 44 anos).

A importância do cuidado com a revelação diagnóstica é também influenciada diretamente por fatores individuais do paciente, sendo citados em vários registros idade e condições socioeconômicas, aliadas ao grau de instrução: "Os pacientes jovens são quem têm mais dificuldades, são os mais arredi os ao diagnóstico". (Dra. Zilda, 44 anos).

"Você tem extremos de pacientes que chegam, que você dá várias informaç̧ões e se você perguntar em um minuto o que foi que você disse, ele não entendeu nada". (Dr. Rômulo, 42 anos).

"O paciente mais instruído é melhor, sem dúvida, porque a gente consegue dividir as responsabilidades muito mais". (Dr. Rômulo, 42 anos).

Seguindo o raciocínio das características individuais, observa-se nitidamente na maioria dos depoimentos que o estadiamento da doença no momento da primeira consulta influencia sobre maneira a construção do vínculo, já que naqueles cujo diagnóstico é precoce as possibilidades de re missão são diversas eevidentes. Porém, infelizmente, ainda muitos chegam com formas avançadas, o que é justificado por alguns pela negligência própria dos pacientes pelo receio da gravidade de sua doença. Por outros, sinaliza-se ainda, além da exagerada burocracia do sistema, para o fato da existência de profissionais despreparados nas portas do sistema que não referenciam de imediato, por simplesmente passar despercebido, aqueles que merecem, atrasando avinda do pacienteao serviço especializado: "Principalmente, eu acho que éo estigma detodo mundo que, àsvezes, fica com medo da doença, com o desconhecimento, eacaba por tolher a oportunidadedeser tratado de uma forma melhor". (Dr. Djalma, 42 anos).

"Falta de estrutura mesmo. Você pedir uma tomografia de tórax para estadiar um câncer de pulmão e demorar quatro meses, no sistema falido que a gente tem, para o paciente retornar com 0 estadiamento, muitas vezes, já mudado e avançado". (Dr. Xavier, 35 anos).

"É a questão da peregrinação que esses pacientes fazem. M uitos vêm do interior eatémesmo aqui da capital, que passam por vários setores, por vários serviços de saúde atéfinalmente chegar aqui. E isso às vezes dificulta bastante, éum dos principaisfatores que levam o paciente a chegar aqui com a neoplasia mais avançada e isso leva a problemas no tratamento, complicações". ( Dra. Fátima, 37 anos). 
Em oncologia, com suas situações peculiares de estigmatização sociocultural, a comunicação deum diagnóstico é, de uma forma geral, recebida pelo paciente como uma má notícia. Ainda que a evolução da história natural da doença e o seu prognóstico sejam multifatoriais - dependendo da compleição física prévia do indivíduo, características imunológicas, bem como estadiamento do tumor - o objeto de estudo da oncologia ainda éencarado como sendo doença incurável edefinitivamenteincapacitante.

Diante disso, percebe-se que as singularidades encontradas na relação médico-paciente oncológico residem em um momento-chave: 0 momento da definição diagnóstica. Por conseguinte, se há quase uma unanimidade com relação à necessidade de se dizer a verdade, há grandes divergências entrea melhor forma defazê-lo.

\section{Entre a mentira e a verdade: as diferenças} comunicacionais entre os médicos

Enquanto Cássio não está sabendo de nada, Dra. Sheila está vivendo o maior drama: "sei de algo sobre uma pessoa que vai fazêla sofrer muito". Essa expectativa angustiante decorre da idéia de que Cássio não seria capaz de elaborar o que vai ser informado, isto é, não ser capaz de fazer as modificações necessárias na estrutura simbólica que os novos significados advindos com a notícia exigirão, prejudicando o prosseguimento das práticas médicas.

Nesse momento, Dra. Sheila busca normas e preceitos, sejam eles éticos, morais e religiosos, para ajudar na situação de ter que contar, ou para não ter que contar algo ao paciente.

Dessa forma, de um lado, ela poderia preferir usar este artifício afirmando que, por principio, nunca falaria o diagnóstico, supondo que nessas horas o paciente precisa de apoio enão de deprimi-lo ainda mais. Fato corroborado na pesquisa no discurso de reservadas entrevistas em que os médicos simplesmente isentam-se de comunicar a doença ao paciente ou optam por mentir, considerando ainda o fato de o paciente poder, inclusive, querer poupar-se a si mesmo evitando o diagnóstico: “ $\mathrm{Na}$ abordagem com o paciente, eu sou bem mentiroso, tento esconder, principalmente quando o prognóstico é ruim. É capaz de o paciente entrar em depressão e dificultar o tratamento". (Dr. Ítalo, 48 anos).

Por outro lado, ela poderia inclinar-se à filosofia de anunciar que semprefalaria para o paciente o seu diagnóstico. Defenderia uma postura mais direta e objetiva, como alguns profissionais, argumentando o direito do paciente de saber seu real quadro: “D eve ser direto, não deve ter meia verdade, objetivo. 0 paciente precisa saber da real situação, mesmo que o prognóstico seja ruim". (Dr. Patrício, 54 anos).

Ou, como a maioria dos médicos da pesquisa, elaborando a informação, eufemizando o nome diagnóstico, evitando a palavra clichê câncer, sem, no entanto, deixar de explanar devidamente sobre a doença. Para estes, o uso de um eufemismo despertaria no paciente a noção de curabilidade de sua doença, afetando diretamente em uma adesão positiva ao tratamento a posteriori: "U sar sinônimos como neoplasia maligna em vez de câncer, que não são conhecidos dele. À medida que a relação vai evoluindo, você vai conseguindo usar as palavras corretas, colocando-se ao lado dele como aliado nessa caminhada. Procurar falar sem termos técnicos, mas não desprovidos da verdade quando tem que explicar para o paciente que 0 tratamento não evoluiu bem e é necessário tentar outras abordagens". (Dra. Velma, 35 anos).

"Existe uma idéia que o paciente não tem estrutura psicológica para saber a verdade. Como médico, eu tenho dever ético dedizer a verdadepro paciente, se elenão quer saber setem câncer éerrado dar um tapa na cara dele e dizer que ele tem câncer. Existem maneiras de você dar má noticia sem ser leviano". (Dr. Bernardo, 29 anos).

0 momento da comunicação diagnóstica, portanto, torna-se crucial no desenvolvimento da relação. 0 médico precisa gerenciar essa situação, levando em conta aspectos psicossociais do paciente, desenvolvendo habilidades relacionais e comunicacionais para tanto. N essa perspectiva deabordagem, observa-senos depoimentos que, apesar da relativa falta de preparo, muitos profissionais demonstram o tato e a habilidade comunicacional condizentes com a orientação do protocolo SPIKES: “Um princípio quea gente tem queter é primeiro ouvir. Saber o queé que ele sabe da doença dele, quais são as expectativas, o que é que elejá sabe. Ouvir mais e falar menos, de princípio é bom, é melhor, porque ouvindo você sabe mais ou menos como lidar. Você pode perguntar ao paciente o queéque ele sabe da doença dele. 0 que éque elejá ouviu falar. Tem paciente que vocêtem que demorar um pouquinho pra dizer e, outros, você tem que ir diretamente, passando uma imagem de uma pessoa que está antenada com o problema do paciente". (Patrício, 54 anos).

Assim, o médico utilizar-se ia desses aspectos como um recurso a mais para o sucesso da relação e da terapêutica. Desse modo, conquistada a 
empatia do paciente, seria possível indicar e executar o mais adequado tratamento para o caso.

Osprotocolosterapêuticos: entre autonomia e paternalismo

Dra. Sheila encontra-se agora em outra situação. Dessa vez, ela recebe em seu ambulatório Elisa, 47 anos, viúva, três filhos, paciente em acompanhamento já há algum tempo pela doutora por carcinoma de pequenas células renais. A presenta-seà D ra. Sheila depois de meses de pós-operatório, queixando-se de uma tosse que a incomoda bastante, inclusive com eventos de escarros hemoptóicos, para os quais aerossóis e antibióticos não surtiram o mínimo efeito, além deuma dor em ombro direito altamente resistente $a$ antiinflamatórios. Ao observar uma radiografia de tórax, Dra. Sheila depara-se com imagens altamente sugestivas de algo que sempre teme: metástases! Um suspiro maior que o feito com Cássio é produzido. E agora? Como dizer a Elisa que sua estratégia terapêutica não atingiu os resultados esperados e que precisava agora de uma abordagem complementar? E se essa dor em ombro direito for advinda de outro processo metastático? Dessa forma, como esclarecer a Elisa que sua situação é crítica, já que esse tipo de neoplasia é tipicamente radioquimioresistente? Como Elisa iria se comportar diante disso? Dra. Sheila não queria vê-la deprimida eque abandonasse seu tratamento.

A angústia enfrentada por Dra. Sheila é uma emoção vivida frequentemente entre os médicos entrevistados. Com relação à abordagem terapêutica, inicialmente, a totalidade reforçou a importância do conhecimento técnico-científico no momento de definição terapêutica, colocando anecessidade de se indicar um tratamento baseado em evidência e que está bem determinado em protocolos definidos. Levando em consideração essa padronização, a grande maioria, entretanto, coloca ainda a importância deselevar em consideração outros fatoresindividuais do paciente, para definir a terapêutica, como questões ligadas ao estilo de vida, condições sociais, desejo dereprodução futuraecapacidadefísica deresistir ao tratamento: "Tem queter o bom senso, para cada paciente. 0 queéque é o melhor para cada paciente? Você não vai fazer uma prostectomia num homem de 85 anos! Apesar deser tudo protocolado, tem queser individualizado para cada paciente". (Dr. Quirino, 38 anos).

"A gente podeaténão fazer uma histerectomia alargada, pensando queela poderia engravidar, mas aí a gente estaria fugindo um pouco do protocolo. A gente sempre tenta ver o futuro da paciente, em termos de reprodução: tenta-se minimizar os efeitos da doença sem prejudicar o tratamento". (Dr. Abelardo, 38 anos).

"Tem certas drogas que não são cobertas pela rede pública, então isso vai depender também do fator social do paciente". (Dra. Zilda, 44 anos).

Uma dificuldade, porém, é registrada por muitos médicos quando há a necessidade de maior agressividade do tratamento, quando a terapêutica recebe o status da própria doença: “M uitas cirurgias são muito mutilantes. Às vezes, a gente tem que fazer cirurgias em crianças, que tem quedesarticular, tirar a perna da criança. Não éuma cirurgia simples, éuma cirurgia que sempre tem a tendência de deixar sequelas". (Dr. Bernardo, 29 anos).

"Você sempre tem que deixar ele ciente do tratamento que você vai fazer, de que efeitos colaterais podem acontecer, consequências e morbidade do próprio tratamento. Porque, muitas vezes, 0 paciente oncológico não morre do câncer, em si, maselepodemorrer do tratamento". (Dra. Letícia, 31 anos).

Em conjunto com essas considerações, a autonomia do pacienteeseu direito de participar da decisão do seu tratamento é uma questão enfatizada por muitos. Seguindo o último passo do protocolo SPIKES, a maioria dos médicos entrevistados revela uma ten dência de respeitarem esse direito do pacientee consultá-los na decisão diagnóstica: "H oje em dia, principalmente, se coloca para o pacienteescolher. Eletem a informação para poder também participar ativamente da decisão do tratamento". (Dra. Núbia, 48 anos).

"A autonomia deletem queser considerada, você não pode impor jamais um tratamento que o pacientetem dificuldadeem aceitar". (Dr. Tiago, 32 anos).

Entretanto, é interessante salientar que essa conduta não é universal; em uma minoria, há discursos totalmente contrários a essa autonomia: "Eu sou ditador. Eu determino o quetem que fazer. M esmo quando o tratamento éradical. Sempre quem decide sou eu. Paciente não tem que decidir do tratamento, paciente não é médico. 0 paciente até pode dizer a vontade dele, como é que quer a vida dele no futuro. Se aquela vontade se encaixar no tratamento, tudo bem, senão sinto muito". (Dr. Ítalo, 48 anos).

É importante, porém, colocar que, em relação ao tratamento, na oncologia especialmente, há um momento em que não há mais possibilidades terapêuticas, como o que praticamente ocorre com Elisa no caso citado anteriormente. 
É o momento dos cuidados paliativos. Muitos entrevistados queixam-se de intensa dificuldade em lidar com essa problemática. Essa dificuldade está relacionada à formação médica e ao despreparo desses profissionais ao lidarem com a terminalidade.

De acordo com Pazin-Filho ${ }^{14}$, a formação médica, atualmente, é centrada na cura, negligenciando, assim, aspectos não menos nobres, como o cuidar e o confortar. Dessa forma, o médico experimenta sentimentos de onipotência, assimilando uma idéia equivocada de que detém poder sobrea cura ea morte. Sentimentos esses que, diante da terminalidade de seus pacientes, transformam-se em frustração e impotência, como relatado por muitos entrevistados: “Eu diria que a dificuldade que nós temos hoje é com nossos clientes que não têm mais esperança de viver. É o doente terminal. É lidar com a terminalidade. As experiências intensas são com os doentes terminais". (Dr. Patrício, 54 anos).

"O que eu acho mais difícil, principalmente nos pacientes que estão conscientes, é dizer que ele não tem maistratamento". (Dra. Letícia, 31 anos).

Por fim, reforçado pelos registros, é importante salientar que a adesão ao tratamento por parte do paciente vai estar diretamente ligada às questões psicossociais da sua vivência, sendo estas modificadoras diretas ou indiretas da percepção de sua doença. Segundo Kubler-Ross ${ }^{15}$, os pacientes com diagnóstico de câncer podem passar por reações emocionais queincluem negação, raiva, barganha, depressão e aceitação. A depender de cada estágio desses, que por sua vez estão relacionados às experiências de vida prévias de cada indivíduo, haveria maior ou menor fidelidade terapêutica, como bem explicitado pela frase de Dr. Otávio: "Acho que, dependendo do critério da negação, o paciente tem depressão e depois vai aceitando, énatural, étemporal. A priori o paciente que encara como uma batalha é o melhor paciente, quefica ao seu lado, durantetodo o tratamento. Aquele que tem uma negação, que pede uma confirmação, que não aceita, é mais difícil tratar, mas acaba cedendo ao tratamento, porque vêm os problemas da doença, e acaba aceitando, concordando com o diagnóstico". (Dr. Otávio, 40 anos).

Observa-se, a partir disso, a importância da esfera psicossocial do pacientena aceitação e adesão ao tratamento, notando-se que a interação junto ao seu contexto, no seu ambiente de convívio, é fundamental para o sucesso. Para se criar, portanto, um bom vínculo médico-pacienteepara que esse binômio seja fortee consistente, o papel da família é essencial.
A família: ajuda ou empecilho?

Diante dos problemas na interação com seus pacientes, Dra. Sheila percebeu que o relacionamento com afamília poderia constituir-sedeuma forte ferramenta na relação com o paciente oncológico, minimizando suas dificuldades, através da cumplicidadee da divisão de responsabilidades. N as consultas posteriores com Cássio, ela pôde sentir o quanto o contato com a família era essencial, pois, a partir do seu apoio, procedeu com suas habilidades para fornecer-Ihe diagnóstico, possibilidades terapêuticas e prognósticas, obtendo relativo sucesso.

0 médico deve manter uma relação de confiança com os familiares e acompanhantes dos pacientes, para que isso reflita em sucesso da terapêutica. 0 maior entendimento do contexto social e cultural no qual o paciente está inserido irá definir até ondeé favorável ou não continuar tratamentos invasivos em pacientes terminais. Essa conduta, até mesmo, poderia evitar uma revolta familiar por fal has terapêuticas ou evoluções desfavoráveis. Esse discurso é corroborado pelo pesquisador Bloom ${ }^{16}$, que observa a importância do apoio social e familiar para queo paciente siga o tratamento indicado, fato, também, explicitado pela maioria dos entrevistados: "Q uando os familiares sentem que o serviço é empenhado no problema, colaboram muito. Serve como apoio e segurança para que o paciente prossiga. Sem isso, elevai falhar no tratamento". (Dra. Úrsula, 33 anos).

"A família tem uma importância como um mediador. As orientações detal hadas de como vai ser o tratamento, como vai ser a cirurgia, a gente conta para a família. A família é uma ponte entre médico e paciente. 0 paciente é muito dependente da família para higiene, alimentação, para consulta, locomoção, para exame". (Dr. Xavier, 35 anos).

Com relação à Elisa, porém, Dra. Sheila não encontrou o que esperava de sua família. Diante da gravidade do quadro e como seus sintomas ainda não interferiam em suas atividades diárias, sua família não permitia que soubesse do real quadro clínico. Argumentavam que Elisa já incorporava uma atitude melancólica e, por isso, se soubesse a verdade iria aprofundar-se em de pressão e não mais desempenharia as atividades que hoje são indispensáveis para a subsistência da família. Diante dessa situação, Dra. Sheila encontrava-se desconfortável.

Existe, no entanto, al guns aspectos negativos em relação ao envolvimento da família no acompanhamento de doentes com câncer. Uma im- 
portante dificuldade da relação com a família registrada em muitos depoimentos é quando se quer esconder do paciente o diagnóstico, fragilizando assim a relação ecriando um binômio saúde doença distorcido do real. Tratar um doente sem que ele saiba por que está sendo tratado prejudica a adesão ao tratamento, já que ele não enten de a gravidade de seu problema. A honestidade ea explicação da doença ao paciente e a sua família são de extrema importância para o vínculo médico-doente, que ébaseado no respeito e na sinceridade: "Q uando a família não quer queo paciente saiba, éuma das situações mais difíceis. A família pede muito para não dizer ao paciente. Eu tenho que convencer a família que o paciente tem 0 direito de saber". (Dr. Humberto, 44 anos).

Ademais, há, em alguns casos, uma supervaIorização da doença pela família, citada em al gumas entrevistas, fragilizando o vínculo e a confiança no tratamento e no prognóstico proposto pelo médico. Para Ariès ${ }^{17}$, a sociedade ocidental convive com a morte através do mecanismo de negação; isso explica o fato de às vezes eles ficarem procurando alternativas de tratamento, quando já não há muito que fazer, podendo assim prolongar mais ainda o sofrimento de seus entes queridos. 0 médico tem o papel de intermediar esse tipo de pensamento no sentido de minimizar fantasias e certos valores sobre a doença: “Então, a maioria dosfamiliares vem pra cá, negando que a pessoa tem um câncer. Têm pacientes que já fizeram todos os níveis terapêuticos, já está, assim, só em seguimento, não tem mais nenhum tipo de tratamento pra fazer, emesmo assim a família sempretecobra al go mais do quetu podes fazer. Acho que el es absorvem muito a dor do paciente, a angústia do paciente, porque se sente, na verdade, impotente em relação aquilo, não poder fazer nada". (Dra. Jordana, 32 anos).

"A relação da família normalmente é uma relação de proteção. Existea tendência de supervalorizar o sofrimento do paciente. Geralmenteo diagnóstico de câncer aproxima as pessoas, algumas intrigas são desfeitas, algumas famílias têm essa superproteção exacerbada que chega a incomodar um pouco. Vocêtem quemostrar para família quais são os fatores que ela realmente tem que monitorizar, para não criar viésnem demenos nem demais". (Dr. Gustavo, 30 anos).
Por fim, importante aqui éestabelecer um vínculo interdisciplinar com a família, pois ela passa a ter apoio emocional, técnico e psicológico. Uma equipe interdisciplinar transmite mais confiança, pois a família observa o interesse da equipe em relação ao paciente, demonstrando a atitude de respeito em referência à dor e ao sofrimento da família e do doente: "Q uando chega a uma fase terminal, a família quer deixar no hospital e isso é ruim. É uma coisa quea sociedade vem construindo. 0 paciente terminal deveria morrer em casa, porque têm a relação de familiares, amigos. No hospital, tem um horário para visita que pode entrar no máximo duas visitas. Realmente éisso que ele queria? Ele queria era morrer num ambiente com a família, amigos". (Dra. Fátima, 37 anos).

\section{Consideraçõesfinais}

A partir desses dados, pode-se perceber que existem nuances na relação médico-paciente oncológico que diferem das demais especialidades. 0 status emocional alterado dos pacientes efamiliares, a abordagem diferenciada de transmitir 0 diagnóstico, uma má notícia easterapêuticasque, em curto prazo, são mais difíceis que a própria doença, tornam-se fatores limitantes aos objetivos da relação médico-paciente, ou seja, construção do vínculo, satisfação do usuário, adesão ao tratamento, qualidade de vida.

Dessa maneira, 0 aperfeiçoamento da humanização do processo de comunicação entre mé dico e paciente tem relação direta com a maior sensibilidade diante do sofrimento e a realidade do paciente frente a sua integridade física, psíquica esocial, enão somentebiológica. Ao médico, cabe o papel de possi bilitar que a relação seja centrada no paciente e não apenas na doença, seguindo o modelo do médico "cuidador": profissional que toma seu paciente por inteiro, dando-Ihe um atendimento holístico.

Diante disso, evidencia-se a maior necessidade de estudos e discussões acerca do assunto, visando a uma melhor formação do médico oncologista no âmbito da relação médico-paciente-família. Mudanças curriculares em cursos de medicina são necessárias na formação de profissionais num modelo biopsicossocial, visando à obtenção de práticas humanizadas, que permitam a compreensão do universo psicológico do paciente. 


\section{Colaboradores}

CM GC H eil Silva trabalhou na concepção, pesquisa, metodologia, discussão e redação final; CHS Rodrigues trabalhou na pesquisa, introdução ediscussão; JC Lima trabalhou na pesquisae discussão; NBH Jucá trabalhou na pesquisa, discussão e revisão crítica; $K L$ Augusto trabalhou na metodologia e revisão crítica; CA Lino trabaIhou na pesquisa, conclusão erevisão crítica; AGN Carvalho e FC Andrade trabal haram na pesquisa eintrodução; JV Rodrigues trabal hou na concepção e discussão e A Caprara trabalhou na concepção e revisão final do artigo.

\section{Referências}

1. Ley P. Communication with patients: improving satisfaction and compliance. London: Croom Helm; 1988.

2. Caprara A, Rodrigues J. A relação assimétrica médico-paciente: repensando o vínculo terapêutico. Cien Saude Colet 2004; 9(1):139-146.

3. Spinsanti S. Chi ha potere sul mio corpo? Nuovi rapporti tra medico e paziente. Roma: Paoline; 1999.

4. Tavares JSC, Trad LAB. M etáforas e significados do câncer de mama na perspectiva de cinco famílias afetadas. Cad Saude Publica 2005; 21(2):426-435.

5. M aruyama SAT, Zago M M F. 0 processo de adoecer do portador de colostomia por câncer. Rev. Latino-Am. Enfermagem 2005; 13(2):216-222.

6. Rezende VL, Derchain SFM, Botega NJ, Sarian LO, Vial DL, Morais SS. Depressão e ansiedade nos cuidadores de mulheres em fase terminal de câncer de mama e ginecológico. Rev. Bras. Ginecol. Obstet 2005; 27(12):737-743.

7. Lorencetti A, Simonetti JP. As estratégias de enfrentamento de pacientes durante 0 tratamento de radioterapia. Rev. Latino-Am. Enfermagem 2005; 13(6): 944-950.

8. Anjos $A C Y$, Zago M M F. A experiência da terapêutica quimioterápica oncológica na visão do paciente. Rev. Latino-Am. Enfermagem 2006; 14(1):33-40.

9. Duarte TP, Andrade AN. Enfrentando a mastectomia: análise dos relatos de mulheres mastectomizadas sobre questões ligadas à sexualidade. Estud. psicol. (Natal) 2003; 8(1):155-163.

10. Buckman R. Breaking bad news: a guide for health care professionals. Baltimore: John Hopkins University Press; 1992.

11. Baile WK, Buckman R, Lenzi R, Glober G, Beale EA, Kudelka AP. SPIKES - a six-step protocol for delivering bad news: application to the patient with cancer. Oncologist 2000; 5(4):302-311.

12. Bastos LAM, Proença MA. A prática anatômica e a formação médica. Rev. Panam. Salud Públ. / Pan Am. J. Public Health 2000; 7(6):395-402.

13. Videla M. Prevención. Buenos Aires: Cinco; 1998.

14. Pazin-Filho A. M orte: Considerações para a prática médica. M edicina (Ribeirão Preto) 2005; 38(1):20-25.

15. Kubler-Ross. Sobre a morte e morrer. São Paulo: M artins Fontes; 1969.

16. Bloom B. All our children learning: A primer for parents, teachers and other educators. New York: M cGraw-Hill;1982.

17. Ariès $P$. H istória da morten 00 cidente: da Idade M édia a nossos dias. Rio de Janeiro: Francisco Alves; 1977.

Artigo apresentado em 02/06/2008

Aprovado em 02/10/2008

Versão final apresentada em 29/10/2008 